\title{
Dielectric Barrier Discharge Plasma Jet (DBDjet) Processed Reduced Graphene Oxide/Polypyrrole/Chitosan Nanocomposite Supercapacitors
}

\author{
Chen Liu ${ }^{1,2}{ }^{,}$Cheng-Wei Hung ${ }^{3}$, I-Chung Cheng ${ }^{3}\left(\mathbb{D}\right.$, Cheng-Che Hsu ${ }^{4}$, I-Chun Cheng ${ }^{5,6,7}$ (D) \\ and Jian-Zhang Chen $1,2,7, *$ (D)
}

1 Graduate Institute of Applied Mechanics, National Taiwan University, Taipei City 10617, Taiwan; R09543009@ntu.edu.tw

2 Advanced Research Center for Green Materials Science and Technology, National Taiwan University, Taipei City 10617, Taiwan

3 Department of Mechanical Engineering, National Taiwan University, Taipei City 10617, Taiwan; r08522744@ntu.edu.tw (C.-W.H.); ichungch@ntu.edu.tw (I.-C.C.)

4 Department of Chemical Engineering, National Taiwan University, Taipei City 10617, Taiwan; chsu@ntu.edu.tw

5 Graduate Institute of Photonics and Optoelectronics, National Taiwan University, Taipei City 10617, Taiwan; iccheng@ntu.edu.tw

6 Department of Electrical Engineering, National Taiwan University, Taipei City 10617, Taiwan

7 Innovative Photonics Advanced Research Center (i-PARC), National Taiwan University, Taipei City 10617, Taiwan

check for updates

Citation: Liu, C.; Hung, C.-W.; Cheng, I.-C.; Hsu, C.-C.; Cheng, I.-C.; Chen, J.-Z. Dielectric Barrier Discharge Plasma Jet (DBDjet) Processed Reduced Graphene Oxide/Polypyrrole/Chitosan Nanocomposite Supercapacitors. Polymers 2021, 13, 3585. https:// doi.org/10.3390/polym13203585

Academic Editor: Rong-Ho Lee

Received: 1 September 2021

Accepted: 11 October 2021

Published: 18 October 2021

Publisher's Note: MDPI stays neutral with regard to jurisdictional claims in published maps and institutional affiliations.

Copyright: (C) 2021 by the authors Licensee MDPI, Basel, Switzerland. This article is an open access article distributed under the terms and conditions of the Creative Commons Attribution (CC BY) license (https:// creativecommons.org/licenses/by/ $4.0 /)$
* Correspondence: jchen@ntu.edu.tw; Tel.: +886-2-336-656-94

Abstract: Reduced graphene oxide (rGO) and/or polypyrrole (PPy) are mixed with chitosan (CS) binder materials for screen-printing supercapacitors (SCs) on arc atmospheric-pressure plasma jet (APPJ)-treated carbon cloth. The performance of gel-electrolyte $\mathrm{rGO} / \mathrm{CS}, \mathrm{PPy} / \mathrm{CS}$, and rGO/PPy/CS SCs processed by a dielectric barrier discharge plasma jet (DBDjet) was assessed and compared. DBDjet processing improved the hydrophilicity of these three nanocomposite electrode materials Electrochemical measurements including electrical impedance spectroscopy (EIS), cyclic voltammetry $(\mathrm{CV})$, and galvanostatic charging-discharging (GCD) were used to evaluate the performance of the three types of SCs. The Trasatti method was used to evaluate the electric-double layer capacitance (EDLC) and pseudocapacitance (PC) of the capacitance. The energy and power density of the three types of SCs were illustrated and compared using Ragone plots. Our experiments verify that, with the same weight of active materials, the combined use of rGO and PPy in SCs can significantly increase the capacitance and improve the operation stability.

Keywords: atmospheric-pressure plasma; dielectric barrier discharge; reduced graphene oxide; polypyrrole; supercapacitor; plasma

\section{Introduction}

Supercapacitors (SCs) have a higher capacitance and lower working voltage than regular capacitors; they are usually used in high-power-density applications requiring fast charging and discharging [1-4]. Their energy storage mechanisms are mainly the electrical double-layer capacitance (EDLC) and pseudocapacitance (PC). EDLC is manifested by rapid ion adsorption/desorption at the electrode/electrolyte interface [5]. This generally occurs in carbon-based electrode materials such as carbon black, carbon nanofibers, carbon nanotubes, and graphenes [6-9]. By contrast, PC is manifested by the Faraday oxidation/reduction reaction of active materials on the electrode surface [10-12]. Because graphene has high conductivity, carrier mobility, and specific surface area, it has been widely used in energy devices such as fuel cells [13], solar cells [14], oxygen evolution reaction electrodes [15], and SCs [16]. However, in practical applications, graphene may 
agglomerate and stack, and this may limit the charge accumulation in the electric double layer $[17,18]$ and result in insufficient energy density. To further increase the capacitance, graphene is often compounded with conductive polymers to couple EDLC and PC [19]. Conducting polymers, such as polypyrrole (PPy), polyaniline, polythiophene, and their derivatives, are candidate active materials for realizing PCs owing to their good conductivity, excellent mechanical flexibility, high theoretical capacitance, and fast redox reaction properties [2,20-22]. Various studies have aimed to combine the advantages of SCs and traditional batteries to achieve high energy density and high power density. In this study, reduced graphene oxides (rGOs) and PPy were selected for the hybrid nanocomposite, and chitosan (CS) was used as a binder and dispersant to screen-print rGO/PPy/CS pastes onto carbon cloth.

Plasma has been extensively used for surface activation and modification [23-25]. Reactive plasma species may create active sites or defects, introduce dopants, and graft surface functional groups on materials surfaces $[12,26,27]$. All of these tailor the surface properties and may alter the surface wettability [1]. Plasma treatment is frequently performed to improve the quality of joining, bonding, or adhesion [28]. Low-pressure plasma operated with a vacuum system has been extensively used in industrial applications. Atmosphericpressure plasma (APP) can be operated in a regular pressure environment without using a vacuum system; this is particularly advantageous for biomedicine and agriculture applications $[29,30]$. By avoiding the need for a vacuum system, the operation cost of APPs can be reduced, making APP an economical viable tool to perform plasma processing when the samples can tolerate environmental cleanliness conditions [4,27,31-33]. Owing to the vigorous interactions of APP reactive species on carbon-based materials, APPs have been extensively used for the rapid processing of carbonaceous materials $[4,7,12,27,31,34,35]$.

In this study, we use a moderate temperature $\left(\sim 500^{\circ} \mathrm{C}\right)$ nitrogen arc atmospheric pressure plasma jet (APPJ) to make a carbon cloth substrate hydrophilic. Because PPy cannot tolerate high temperature, near room temperature $\left(<40{ }^{\circ} \mathrm{C}\right) \mathrm{He}-2 \% \mathrm{O}_{2}$ dielectric barrier discharge plasma jet (DBDjet) is used to treat the screen-printed $\mathrm{rGO} / \mathrm{PPy} / \mathrm{CS}$ for further improving its hydrophilicity, thereby facilitating its contact with the gel electrolyte. With the same material weight loading (i.e., the same weight of active materials), we compare the performance of SCs made with $\mathrm{rGO} / \mathrm{CS}$, PPy/CS, and rGO/PPy/CS. Our experimental results show improved capacitance and long-term operation stability when using rGO and PPy together as the active materials for SCs.

\section{Materials and Methods}

\subsection{Preparation of $r G O / P P y / C S, r G O / C S$, and PPy/CS Pastes}

CS (obtained from shrimp shells, deacetylation degree: $>75 \%$, Sigma Aldrich, Burlington, MA, USA) acetic acid solution was prepared by stirring a mixture of $0.3 \mathrm{~g}$ of CS powder and $20 \mathrm{~mL}$ of $0.1 \mathrm{M}$ acetic acid (purity: $>99.5 \%$, AUECC, Kaohsiung, Taiwan) at $50{ }^{\circ} \mathrm{C}$ for $2 \mathrm{~h}$. After natural cooling, the mixture was then stirred at room temperature for $1 \mathrm{~h}$ before use. Next, three types of active materials were introduced: $0.1 \mathrm{~g}$ of rGO (thickness: $<5 \mathrm{~nm}$, chip diameter: $0.1-5 \mu \mathrm{m}$, oxygen content: $5-10 \%$, purity: $>99 \%$, Golden Innovation Business, New Taipei City, Taiwan), $0.1 \mathrm{~g}$ of PPy (conductivity: 10-50 S/cm, water: $<1.0 \%$, Sigma Aldrich, Burlington, MA, USA), and mixture of $0.05 \mathrm{~g}$ rGO and $0.05 \mathrm{~g}$ PPy. Then the powdered active material was mixed with $1.5 \mathrm{~g}$ ethanol (purity: 95\%, Echo Chemical, Miaoli, Taiwan) and $3.6 \mathrm{~g}$ of CS acetic acid solution and stirred with a magnetic stirrer. Finally, the resulting mixture was concentrated by using a rotary evaporator at $50{ }^{\circ} \mathrm{C}$ for $150 \mathrm{~s}$.

\subsection{Fabrication of $r G O / P P y / C S, r G O / C S$, and PPy/CS Electrodes}

A rectangular carbon cloth $(3 \mathrm{~cm} \times 4 \mathrm{~cm})$ was used as the current collector. First, the carbon cloth was pre-treated using a nitrogen DC pulse APPJ (as shown in Figure 1) for $30 \mathrm{~s}$. The treatment process is described in a previous study [1]. After the APPJ treatment, three types of active materials were screen printed on the carbon cloth with an area of 
$1.5 \times 2 \mathrm{~cm}^{2}$. Next, the sample was calcined at $80{ }^{\circ} \mathrm{C}$ for $10 \mathrm{~min}$ in an oven. Finally, a DBDjet (as shown in Figure 1) was applied to post-treat the sample three times with a scanning speed of $2 \mathrm{~mm} / \mathrm{s}$. The carrier gas of the DBDjet was mixture with $98 \%$ helium and $2 \%$ oxygen.
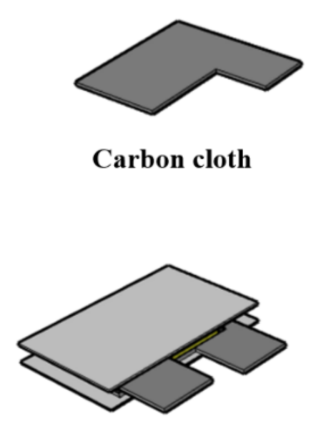

Flexible supercapacitor
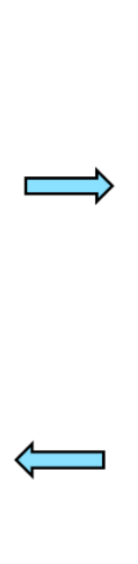

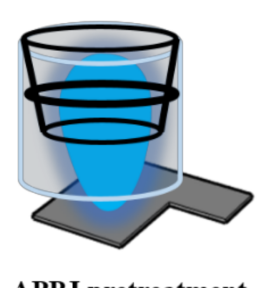

APPJ pretreatment

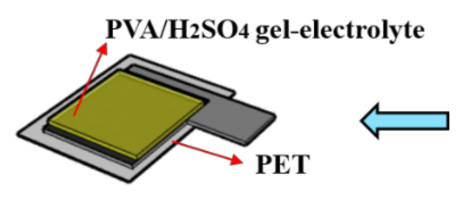

Electrolyte coating
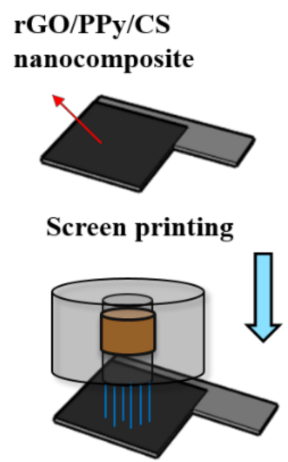

DBDjet post-treatment

Figure 1. Schematic diagram of fabrication process of flexible SCs.

\subsection{Preparation of Gel-Electrolyte Solution}

First, $1.5 \mathrm{~g}$ of polyvinyl alcohol (PVA; MW: 850,000-124,000, 99+\% hydrolysis, Sigma Aldrich) powder was slowly added to $15 \mathrm{~mL}$ of $1 \mathrm{M}$ sulfuric acid (purity: $95-97 \%$, AUECC, Burlington, MA, USA). Then, the mixture was stirred at $200 \mathrm{rpm}$ at $70^{\circ} \mathrm{C}$ for $6 \mathrm{~h}$. Then, the gel-electrolyte solution was naturally cooled and stirred at $300 \mathrm{rpm}$ at room temperature.

\subsection{Fabrication of Symmetric Sandwich-Type SCS}

First, $1 \mathrm{~mL}$ of gel electrolyte solution was dropped on the DBDjet post-treated $\mathrm{rGO} / \mathrm{CS}$, $\mathrm{PPy} / \mathrm{CS}$, or rGO/PPy/CS nanocomposite-coated carbon cloth. The sample was then naturally dried for $24 \mathrm{~h}$. The gel electrolyte coating step was repeated three times. Finally, the symmetrical sandwich-type SC was combined with two gel electrolyte-coated electrodes with the same active materials. Light pressing was applied against the sides of the gel electrolyte to assure the flatness of the device. Figure 1 shows a schematic of the process flowchart.

\subsection{Characterization of $r G O / P P y / C S, r G O / C S$, and PPy/CS Nanocomposites and SCS}

The water contact angles of the rGO/CS, PPy/CS, or rGO/PPy/CS nanocompositecoated carbon cloths were measured by using a goniometer (Sindatek, Model 100SB, Taipei City, Taiwan). Scanning electron microscopy (SEM, JSM-IT100, JEOL, Tokyo, Japan) and X-ray photoelectron spectroscopy (XPS, Sigma Probe, Thermo VG-Scientific) were used to check the surface morphology and surface chemical bonding status of the rGO/PPy/CS, $\mathrm{rGO} / \mathrm{CS}$, and PPy/CS-coated carbon cloths. An electrochemical workstation (Autolab PGSTAT204, Metrohm, Utrecht, The Netherlands) was used to perform cyclic voltammetry (CV) $(0-0.8 \mathrm{~V}$, potential scan speed: $2-200 \mathrm{mV} / \mathrm{s})$, galvanostatic charging discharging (GCD, $0-0.8 \mathrm{~V}$, constant current: $0.25,0.5,1,3$, and $5 \mathrm{~mA}$ ), and electrochemical impedance spectroscopy (EIS, $0.1-100,000 \mathrm{~Hz}$ ) measurements in a two-electrode configuration to characterize the SC [1].

\section{Results and Discussion}

\subsection{Surface Morphology of $r G O / C S, P P y / C S$, and $r G O / P P y / C S$ Electrodes}

Figure 2 shows the SEM images of the electrodes made with $\mathrm{rGO} / \mathrm{CS}, \mathrm{PPy} / \mathrm{CS}$, and $\mathrm{rGO} / \mathrm{PPy} / \mathrm{CS}$ pastes on carbon cloth after DBDjet post-treatment, respectively. The highermagnification SEM images with rGO/CS paste reveal the sheet-like structure of rGO nano- 
flakes. rGOs with a large specific surface area typically provide EDLC for SCs [36]. The SEM images of the PPy/CS electrode show spherical PPy particles with coarse surfaces [37]. The higher-magnification SEM images with $\mathrm{rGO} / \mathrm{PPy} / \mathrm{CS}$ electrode show a combined structure, with a sheet-like structure of rGOs and spherical particles of PPy.

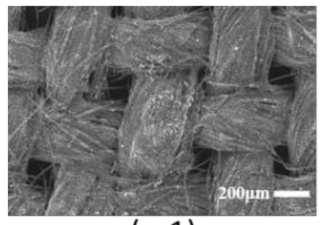

$(\mathrm{a}-1)$

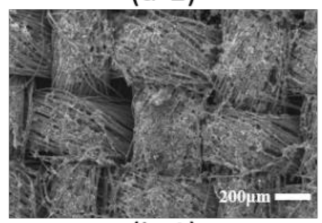

(b-1)

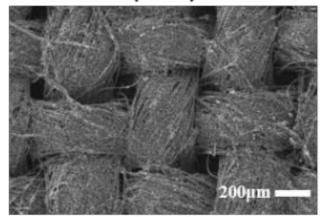

(c-1)

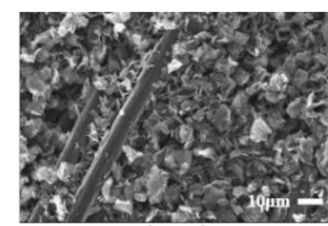

$(a-2)$

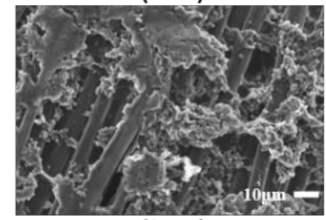

(b-2)

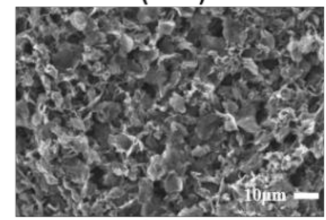

(c-2)

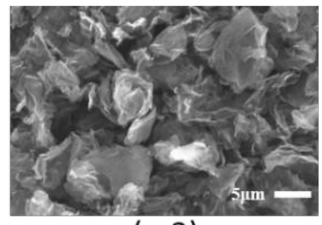

$(a-3)$

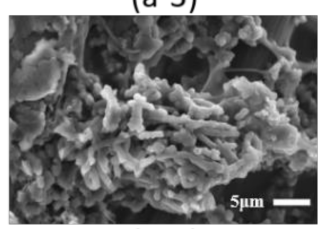

(b-3)

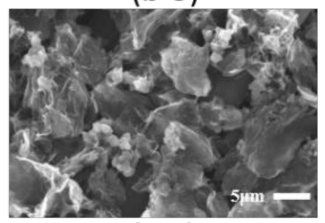

(c-3)

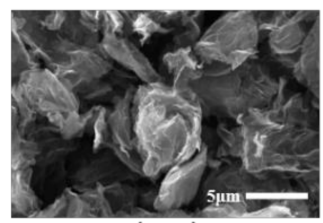

$(a-4)$

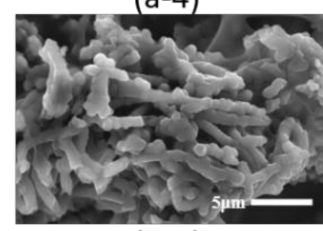

(b-4)

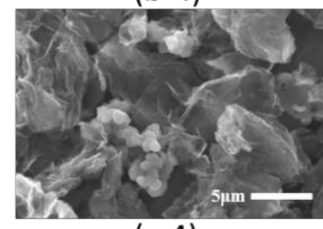

(c-4)

Figure 2. SEM images. rGO/CS electrodes with (a-1) $70 \times,(\mathbf{a}-\mathbf{2}) 1000 \times,(\mathbf{a}-\mathbf{3}) 3000 \times$, and (a-4) 5000 $\times$ magnification; PPy/CS electrodes with (b-1) $70 \times,(\mathbf{b}-2) 1000 \times,(\mathbf{b}-3) 3000 \times$, and (b-4) 5000× magnification; and rGO/PPy/CS electrodes with (c-1) $70 \times,(c-2) 1000 \times,(c-3) 3000 \times$, and (c-4) $5000 \times$ magnification.

\subsection{Hydrophilicity Assessment and XPS Results of $r G O / C S, P P y / C S$ and $r G O / P P y / C S$ Electrodes}

Figure 3a shows that the water contact angle of pristine carbon cloth is $115.7^{\circ}$, indicating its hydrophobicity nature. After nitrogen arc APPJ pre-treatment, owning to the synergistic effect of high temperature and reactive plasma species, the carbon cloth became hydrophilic, and the droplet was immediately absorbed into the carbon cloth, as shown in Figure 3b [38]. Figure 3c-1,d-1,e-1 respectively shows the water contact angles of screen-printed $\mathrm{rGO} / \mathrm{CS}$, PPy/CS, and $\mathrm{rGO} / \mathrm{PPy} / \mathrm{CS}$ pastes on carbon clothes before DBDjet treatment. The PPy/CS-coated carbon cloth shows a water contact angle of $90.8^{\circ}$ owing to the strong hydrophobicity of PPy. After DBDjet treatment on rGO/CS, PPy/CS, and $\mathrm{rGO} / \mathrm{PPy} / \mathrm{CS}$-coated carbon clothes, the material surfaces became hydrophilic and absorbed water droplets, as shown in Figure 3c-2,d-2,e-2, respectively. The low temperature DBDjet processing can avoid the thermal damage on the coated materials (especially PPy) and simultaneously improve the wettability [1], thereby enhancing the interfacial contact with the follow-up-coated gel electrolytes.

XPS analyses were conducted to identify the chemical elements. The electrode containing rGOs showed higher C-C/C-O peak area ratios in XPS C1s spectra compared to that without rGOs. Further, the N1s spectra indicated the $-\mathrm{NH}^{+}$- content with the PPy coating, suggesting the successful deposition of PPy. Figures S1-S4 show the XPS results, and Tables S1-S4 show the corresponding element proportions (Supplementary Materials).

\subsection{EIS}

Figure 4 shows the Nyquist plots of SCs with rGO/CS, PPy/CS, and rGO/PPy/CS nanocomposites. The inset of Figure 4 shows magnified view of the high frequency region. Table 1 lists the capacitive contribution of SCs with $\mathrm{rGO} / \mathrm{CS}$, PPy/CS, and rGO/PPy/CS nanocomposites. In the low frequency region, the curves are straight lines, corresponding to the Warburg diffusion impedance $\left(\mathrm{W}_{0}\right)$. A straight line with a steeper slope indicates an electric double layer (EDL) with a compact structure. Conversely, one with a milder slope 
tends to indicate an ion diffusion in the capacitor. The SC with rGO/CS nanocomposites is more EDL-like; by contrast, that with PPy/CS nanocomposites is more ion-diffusionlike. Ideally, the SC with $\mathrm{rGO} / \mathrm{PPy} / \mathrm{CS}$ nanocomposites should exhibit a combination of these two effects. In the high-frequency region, a small recessed semicircle can be observed, indicating the parallel combination of the charge transfer resistance $\left(\mathrm{R}_{\mathrm{CT}}\right)$ and the constant phase element (CPE). The lower charge transfer resistance (indicated by a smaller semicircle) corresponds to a higher electron propagation speed. This is an important factor in fast redox systems, especially for SCs. However, among all SCs, there is no obvious difference in this regard. The difference of the Warburg diffusion impedance dominates the influence of each material on the SC. CPE corresponds to the interfacial capacitance between the electrode and the electrolyte. However, there is no obvious difference between each CPE value. Here, it should be noted that the intercept at the $x$-axis represents the series resistance $\left(R_{S}\right)$.

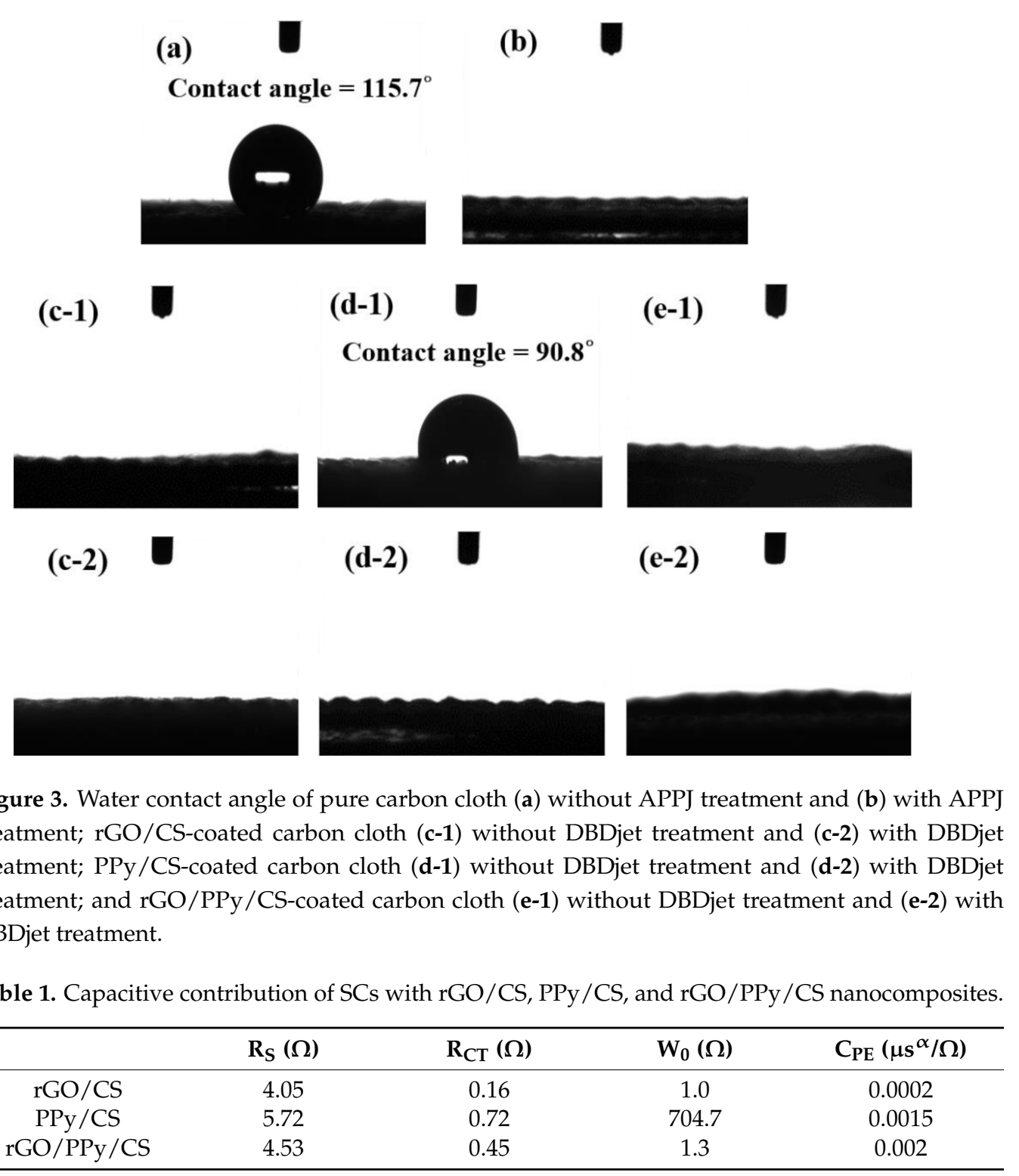

\section{4. $C V$ Measurement}

Figure 5 shows the cyclic voltammetry (CV) measurement results of three different nanocomposite SCs at different scan rates. The enclosed area monotonically increased with 
the potential scan rate. The potential window and potential scan rate were set as $0-0.8 \mathrm{~V}$ and $2-200 \mathrm{mV} / \mathrm{s}$, respectively. The areal capacitance can be calculated as [39]

$$
C_{A}=\frac{A}{s \times v \times \Delta V}
$$

Here, $C_{A}$ is the areal capacitance $\left(\mathrm{mF} / \mathrm{cm}^{2}\right) ; A$, the convolution area of the $\mathrm{CV}$ curves $(\mathrm{mW}) ; \Delta V$, the potential window $(\mathrm{V}) ; v$, the potential scan rate $(\mathrm{V} / \mathrm{s})$; and $s$, the geometric area of the active part $\left(\mathrm{cm}^{2}\right)$. An SC with $\mathrm{rGO} / \mathrm{CS}$ nanocomposites mainly exhibits the EDLC, and therefore, the CV curve is more squarish [40]. By comparison, an SC with $\mathrm{PPy} / \mathrm{CS}$ nanocomposites shows a much more irregular CV curve. This indicates the apparent oxidation-reduction reaction of PPy [41]. The SC with $\mathrm{rGO} / \mathrm{PPy} / \mathrm{CS}$ nanocomposites shows an obvious redox peak, and its areal capacitance $\left(45.32 \mathrm{mF} / \mathrm{cm}^{2}\right)$ is much higher than that of $\mathrm{rGO} / \mathrm{CS}\left(23.37 \mathrm{mF} / \mathrm{cm}^{2}\right)$ and PPy/CS $\left(24.34 \mathrm{mF} / \mathrm{cm}^{2}\right)$ at the scan rate of $2 \mathrm{mV} / \mathrm{s}$. In this case, the areal capacitance of the SC with $\mathrm{rGO} / \mathrm{PPy} / \mathrm{CS}$ nanocomposite is boosted by both EDLC and PC. The combination of rGO and PPy dramatically improves the SC performance.

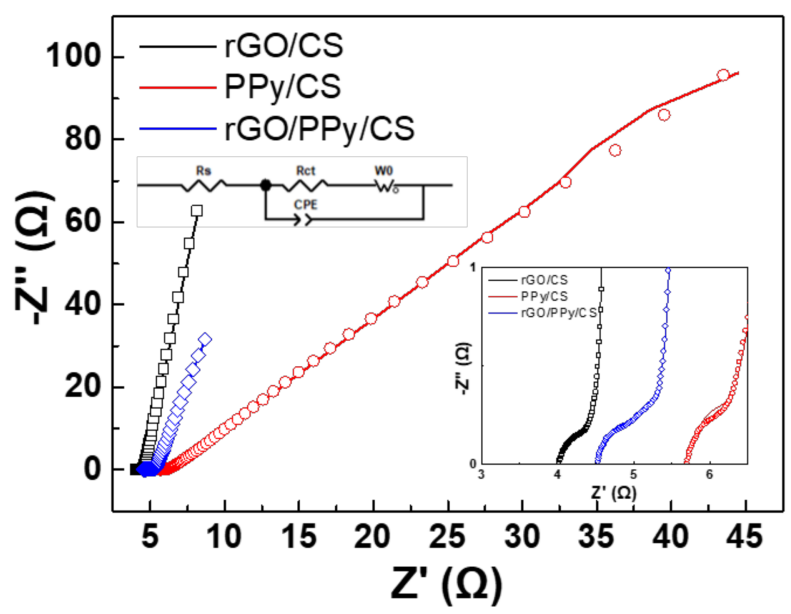

Figure 4. Nyquist plots of SCs with rGO/CS, PPy/CS, and rGO/PPy/CS nanocomposites.

(a)

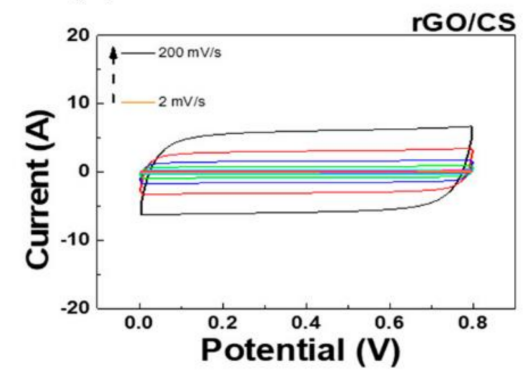

(b)

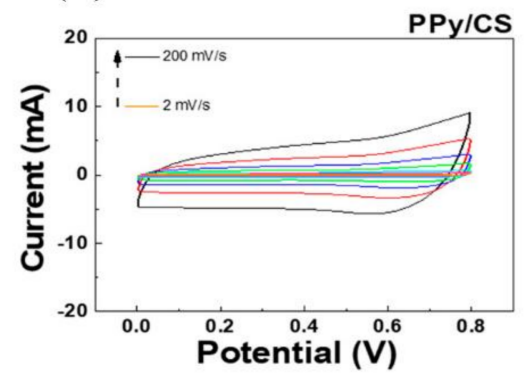

(c)

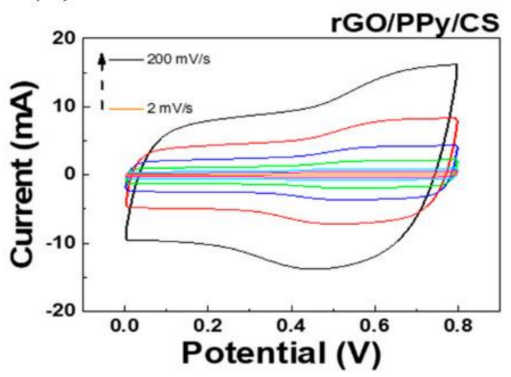

Figure 5. Cyclic voltammetry curves of (a) rGO/CS, (b) PPy/CS, (c) rGO/PPy/CS nanocomposite SCs at different scan rates.

\subsection{Trasatti's Plots}

Trasatti's plots can be used to determine the contributions of the EDLC and the PC [42]. Trasatti's theory is used to divide the storage mechanism into two different types: surface charge $\left(\mathrm{C}_{\text {out }}\right)$ and diffusion control charge $\left(\mathrm{C}_{\text {in }}\right)$. Different mechanism dominates in different potential scan rate ranges [43]. $C_{\text {out }}$ is mainly formed by the accumulated charge on the active material surface, which is the origin of EDLC. Conversely, the charges stored in the PC-based material contribute to $C_{i n}$. By extrapolation, the two types of capacitance 
values can be evaluated. When the voltage scan rate approaches infinity, the $\mathrm{C}_{\text {out }}$ dominates the capacitance value. When the voltage scan rate approaches zero, there is enough reaction time for the charge to diffuse into the active material, and charges can be stored internally and externally $\left(\mathrm{C}_{\text {total }}=\mathrm{C}_{\text {in }}+\mathrm{C}_{\text {out }}\right)[44,45]$.

Figure 6 shows Trasatti's plots of SCs with $\mathrm{rGO} / \mathrm{CS}$, PPy/CS, and rGO/PPy/CS nanocomposites. Figure 6 a shows the relationship between $1 / C_{A}$ and $V^{0.5}$; this straightfitted line can be used to extrapolate $C_{\text {total }}$. Figure $6 \mathrm{~b}$ shows the relationship between $C_{A}$ and $v^{-0.5}$; it can be used to extrapolate $\mathrm{C}_{\text {out }}$. Table 2 shows the calculated capacitance contribution. The SCs with rGO/CS nanocomposites exhibit higher EDLC (79.4\%), whereas those with PPy/CS nanocomposites exhibit roughly equal contributions of EDLC and PC (50\%:50\%). The rGOs added into PPy/CS to form rGO/PPy/CS boost the EDLC effect to achieve the best performance with the corresponding capacitive contribution percentage of EDLC and PC being 75\%:25\%.

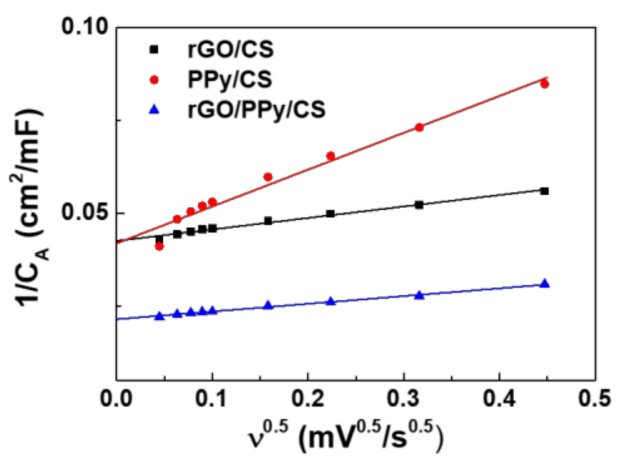

(a)

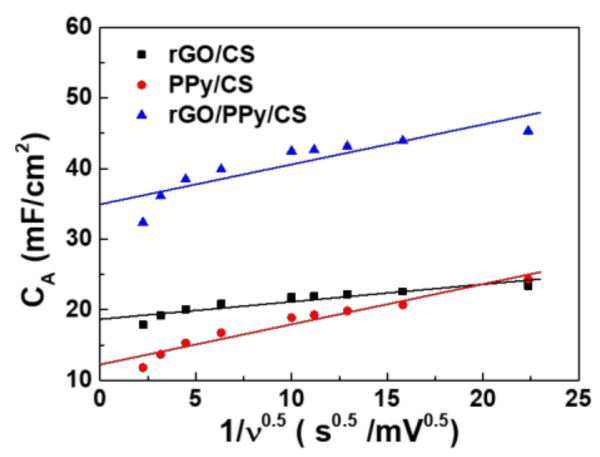

(b)

Figure 6. Trasatti's plots of SCs with rGO/PPy/CS, rGO/CS, and PPy/CS nanocomposites: (a) $1 / \mathrm{C}_{\mathrm{A}}$ vs. $v^{1 / 2}$. (b) CA vs. $1 / v^{1 / 2}$.

Table 2. Capacitive contributions of SCs with rGO/CS, PPy/CS, and rGO/PPy/CS nanocomposites.

\begin{tabular}{ccccc}
\hline & $\begin{array}{c}\text { Ctotal } \\
\left(\mathbf{m F} / \mathbf{c m}^{\mathbf{2}}\right)\end{array}$ & $\begin{array}{c}\text { Cin } \\
\left(\mathbf{m F} / \mathbf{c m}^{\mathbf{2}}\right)\end{array}$ & $\begin{array}{c}\text { Cout } \\
\left(\mathbf{m F} / \mathbf{c m}^{\mathbf{2}}\right)\end{array}$ & $\begin{array}{c}\text { Capacitive Contribution } \\
\text { (EDLC:PC) } \mathbf{( \% )}\end{array}$ \\
\hline $\mathrm{rGO} / \mathrm{CS}$ & 23.5 & 18.7 & 4.9 & $79.4: 20.6$ \\
$\mathrm{PPy} / \mathrm{CS}$ & 23.9 & 12.2 & 11.6 & $51.3: 48.7$ \\
$\mathrm{rGO} / \mathrm{PPy} / \mathrm{Cs}$ & 46.6 & 34.9 & 11.7 & $75.0: 25.0$ \\
\hline
\end{tabular}

\subsection{GCD}

Figure 7 shows the GCD results of the SCs with $\mathrm{rGO} / \mathrm{PPy} / \mathrm{CS}, \mathrm{rGO} / \mathrm{CS}$, and PPy/CS nanocomposites. GCD measurements can be used to calculate the areal capacitance values as [46]

$$
C_{A}=\frac{2 I \times T}{S \times \Delta V}
$$

Here, $C_{A}$ is the areal capacitance $\left(\mathrm{mF} / \mathrm{cm}^{2}\right) ; I$, the discharging current $(\mathrm{mA}) ; T$, the discharging time (s); $\Delta V$, the potential window $(V)$; and $\mathrm{s}$, the geometric area of the active material $\left(\mathrm{cm}^{2}\right)$. Table 3 lists the areal capacitance values calculated from the GCD curves in Figure 7. The SC with $\mathrm{rGO} / \mathrm{PPy} / \mathrm{CS}$ nanocomposites shows the best performance with an areal capacitance of $72.79 \mathrm{mF} / \mathrm{cm}^{2}$ under a discharging current of $1 \mathrm{~mA}$; this is $2-3$ times higher than that achieved under the other two conditions. This result agrees with the CV results. With the PPy/CS composite, the slope of the GCD curve changes for a low discharging current. This phenomenon indicates that PPy performs a more obvious redox reaction [1]. The parameter used to compare the performance of SCs is gravimetric-specific capacitance. In our case, however, the measurement of weight change due to screenprinted materials in our SCs could lead to large error in determining gravimetric-specific 
capacitance because of the materials loading, and therefore, we used areal capacitance to compare our results. In addition, the areal capacitance and/or volumetric capacitance is more useful to describe the specification in commercial SCs. Table S5 (Supplementary Materials) lists the $C_{A}$ performance of various composite SCs. The $C_{A}$ value of SC with $\mathrm{rGO} / \mathrm{PPy} / \mathrm{CS}$ nanocomposite is on par with most of the results in Table S5.

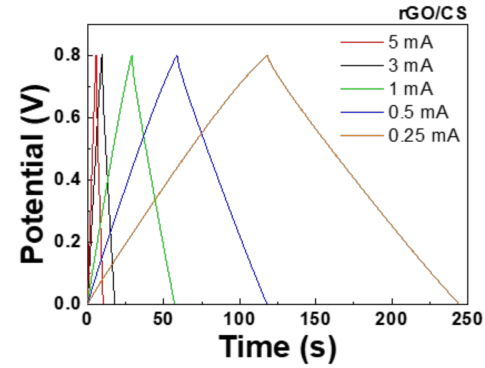

(a)

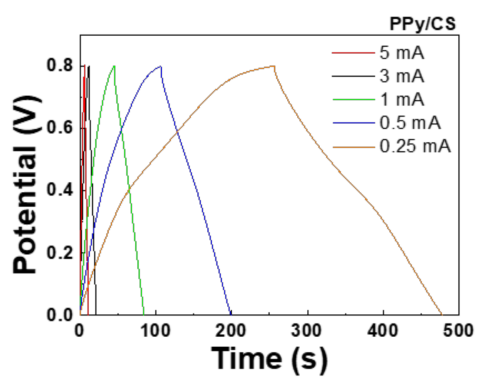

(b)

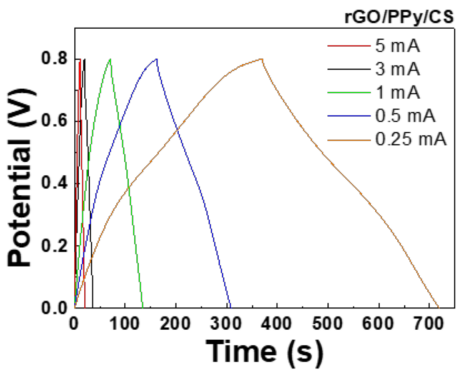

(c)

Figure 7. GCD curves of the SCs with (a) rGO/CS, (b) PPy/CS, and (c) rGO/PPy/CS nanocomposites under different discharge currents.

Table 3. Areal capacitance of SCs analyzed from GCD measurement.

\begin{tabular}{cccccc}
\hline \multicolumn{7}{c}{ Areal Capacitance $\left(\mathbf{m F} / \mathbf{c m}^{2}\right)$} \\
\hline & $\mathbf{5}$ & $\mathbf{3}$ & $\mathbf{1}$ & $\mathbf{0 . 5}$ & $\mathbf{0 . 2 5}$ \\
\cline { 2 - 6 } & $\mathbf{5}$ & 21.25 & 23.42 & 24.64 & 26.23 \\
$\mathrm{rGO} / \mathrm{CS}$ & 19.30 & 25.01 & 32.77 & 38.57 & 46.34 \\
$\mathrm{PPy} / \mathrm{CS}$ & 20.97 & 43.32 & 52.91 & 61.33 & 72.79 \\
$\mathrm{rGO} / \mathrm{PPy} / \mathrm{Cs}$ & 38.44 & &
\end{tabular}

\subsection{Ragone Plots}

Ragone plots are used to evaluate the energy and power density of the SCs. The areal energy density and areal power density can respectively be calculated as [47]

$$
\begin{aligned}
E_{A} & =\frac{C_{A} \times \Delta V^{2}}{7.2} \\
P_{A} & =\frac{3.6 \times E_{A}}{T}
\end{aligned}
$$

where $E A$ is the energy density $\left(\mu \mathrm{Wh} / \mathrm{cm}^{2}\right) ; C_{A}$, the areal capacitance from the GCD measurement $\left(\mathrm{mF} / \mathrm{cm}^{2}\right) ; \Delta V$, the potential window $(V) ; P A$, the power density $\left(\mathrm{mW} / \mathrm{cm}^{2}\right)$; and $T$, the discharging time $(s)$.

Figure 8 shows Ragone plots of the SCs with rGO/CS, PPy/CS, and rGO/PPy/CS nanocomposites. The SC with $\mathrm{rGO} / \mathrm{PPy} / \mathrm{CS}$ nanocomposites exhibited the best achieved energy density of $6.5 \mu \mathrm{Wh} / \mathrm{cm}^{2}$ under a discharging current of $0.25 \mathrm{~mA}$ and the best achieved power density of $1.333 \mathrm{~mW} / \mathrm{cm}^{2}$ under a discharging current of $5 \mathrm{~mA}$. The nanocomposite materials increased the energy density. By contrast, the SCs with rGO/CS and PPy/CS nanocomposites showed poor performance, indicating the advantages of mixing rGOs, PPy, and CS to form nanocomposites.

\subsection{Stability and Bending Tests}

Figure 9a shows the CV stability test results of the SCs with a potential scanning rate of $200 \mathrm{mV} / \mathrm{s}$. After 10,000 cycles, rGO/CS SC retains $90 \%$ of the initial areal capacitance, whereas PPy/CS retains only 43\% owing to the poor PPy stability in long-term operation. $\mathrm{rGO} / \mathrm{PPy} / \mathrm{CS}$ SC retains $88 \%$ of the initial capacitance value. Adding rGOs to PPy/CS clearly improves the CV stability. 


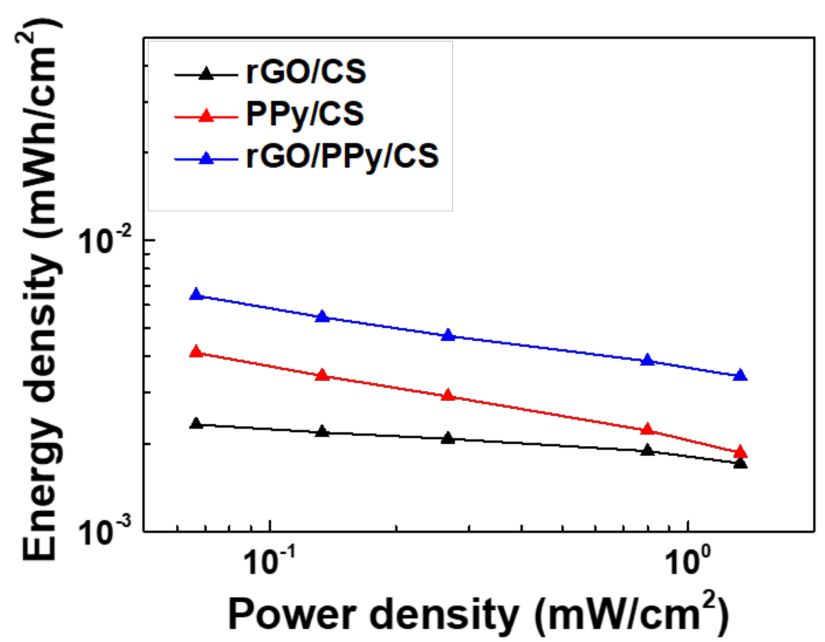

Figure 8. Ragone's plots of SCs with rGO/CS, PPy/CS and rGO/PPy/CS nanocomposite.

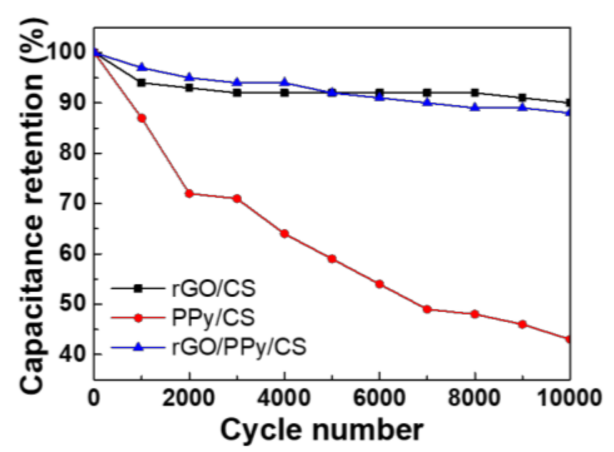

(a)

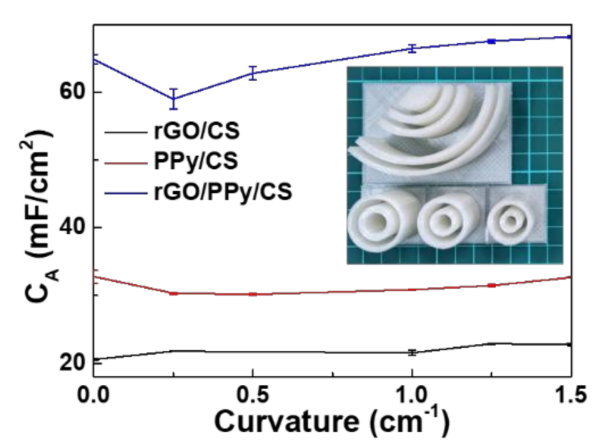

(b)

Figure 9. (a) Cycling stability test with a potential scan rate of $200 \mathrm{mV} / \mathrm{s}$. (b) Bending test under different curvatures with the discharging current of $1 \mathrm{~mA}$.

Figure $9 \mathrm{~b}$ shows the bending test results of the SCs under different curvatures. The capacitance values are measured by GCD under the discharging current of $1 \mathrm{~mA}$. The capacitance values fluctuate randomly as the curvature increases. Interestingly, the capacitance values increase at a certain curvature. All SCs function well under bending.

\section{Conclusions}

This study evaluates the screen-printed $\mathrm{rGO} / \mathrm{CS}$, PPy/CS, and rGO/PPy/CS SCs with active materials of the same weight. The GCD results show that the areal capacitance of $\mathrm{rGO} / \mathrm{CS}$, PPy/CS, and $\mathrm{rGO} / \mathrm{PPy} / \mathrm{CS} S \mathrm{Ss}$ is $26.23,46.34$, and $72.79 \mathrm{mF} / \mathrm{cm}^{2}$, respectively. Combining rGO and PPy clearly results in improved areal capacitance and improved 10,000-cycle CV stability. The EIS results indicate that the SC with $\mathrm{rGO} / \mathrm{CS}$ nanocomposites is more EDL-like, whereas the one with PPy/CS nanocomposites is more ion-diffusion-like. Trasatti analysis indicates that the addition of rGOs increases the contribution of EDLC. All three types of SCs perform well under bending.

Supplementary Materials: The following are available online at https: / www.mdpi.com/article/ 10.3390/polym13203585/s1. Figure S1. XPS analysis of electrodes for (a) rGO/CS, (b) PPy/CS, and (c) rGO/PPy/CS pastes on carbon cloth. Table S1. Atomic ratios of C, O, N, Na, S, and Si as calculated from XPS spectra. Figure S2. XPS spectra of C1s for (a) rGO/CS, (b) PPy/CS, and (c) $\mathrm{rGO} / \mathrm{PPy} / \mathrm{CS}$ paste on carbon cloth. Table S2. XPS C1s spectra of electrode with $\mathrm{rGO} / \mathrm{CS}, \mathrm{PPy} / \mathrm{CS}$, and rGO/PPy/CS pastes on carbon cloth. Figure S3. XPS spectra of N1s for (a) rGO/CS, (b) PPy/CS, 
and (c) rGO/PPy/CS paste on carbon cloth. Table S3. XPS N1s spectra of electrode with rGO/CS, $\mathrm{PPy} / \mathrm{CS}$, and rGO/PPy/CS pastes on carbon cloth. Figure S4. XPS spectra of O1s for (a) rGO/CS, (b) PPy/CS, and (c) rGO/PPy/CS pastes on carbon cloth. Table S4. XPS O1s spectra of electrode with rGO/CS, PPy/CS, and rGO/PPy/CS pastes on carbon cloth. Table S5. Comparison of areal capacitance of SCs with different materials listed in literatures.

Author Contributions: Conceptualization, J.-Z.C., I.-C.C. (I-Chun Cheng) and C.-C.H.; methodology, J.-Z.C., I.-C.C. (I-Chung Cheng), I.-C.C. (I-Chun Cheng) and C.-C.H.; software, C.L.; validation, J.-Z.C., C.L. and C.-W.H.; investigation, C.L.; data curation, C.L.; writing-original draft preparation, C.L.; writing-review and editing, J.-Z.C.; supervision, J.-Z.C. All authors have read and agreed to the published version of the manuscript.

Funding: This study is financially supported by the "Advanced Research Center for Green Materials Science and Technology" from the Featured Area Research Center Program of the Higher Education Sprout Project by the Ministry of Education (110L9006) and the Ministry of Science and Technology in Taiwan (MOST 110-2634-F-002-043 and MOST 108-2221-E-002-088-MY3). This work is also partly supported by the Ministry of Science and Technology in Taiwan under grant no. MOST 110-3116-F-002-002.

Institutional Review Board Statement: Not applicable.

Informed Consent Statement: Not applicable.

Data Availability Statement: The data presented in this study are available on request from the corresponding author.

Acknowledgments: XPS experiments were conducted by Jheng-Wun Lin at the Instrument Center of National Dong Hwa University.

Conflicts of Interest: The authors declare no conflict of interest.

\section{References}

1. Tseng, C.-H.; Hsin, J.-C.; Tsai, J.-H.; Chen, J.-Z. Dielectric-barrier-discharge jet treated flexible supercapacitors with carbon cloth current collectors of long-lasting hydrophilicity. J. Electrochem. Soc. 2020, 167, 116511. [CrossRef]

2. Liu, Y.; Murtaza, I.; Shuja, A.; Meng, H. Interfacial modification for heightening the interaction between PEDOT and substrate towards enhanced flexible solid supercapacitor performance. Chem. Eng. J. 2020, 379, 122326. [CrossRef]

3. Guan, B.; Li, Y.; Yin, B.; Liu, K.; Wang, D.; Zhang, H.; Cheng, C. Synthesis of hierarchical NiS microflowers for high performance asymmetric supercapacitor. Chem. Eng. J. 2017, 308, 1165-1173. [CrossRef]

4. Liu, L.; Ye, D.; Yu, Y.; Liu, L.; Wu, Y. Carbon-based flexible micro-supercapacitor fabrication via mask-free ambient micro-plasmajet etching. Carbon 2017, 111, 121-127. [CrossRef]

5. $\quad$ Meng, J.; Nie, W.; Zhang, K.; Xu, F.; Ding, X.; Wang, S.; Qiu, Y. Enhancing electrochemical performance of graphene fiber-based supercapacitors by plasma treatment. ACS Appl. Mater. Interfaces 2018, 10, 13652-13659. [CrossRef]

6. Zhang, X.; Wang, W.; Lu, J.; Hua, L.; Heng, J. Reversible heat of electric double-layer capacitors during galvanostatic charging and discharging cycles. Thermochim. Acta 2016, 636, 1-10. [CrossRef]

7. Chien, H.-H.; Cheng, Y.-C.; Hao, Y.-C.; Hsu, C.-C.; Cheng, I.-C.; Yu, S.; Chen, J.-Z. Nitrogen DC-pulse atmospheric-pressureplasma jet (APPJ)-processed reduced graphene oxide (rGO)-carbon black (CB) nanocomposite electrodes for supercapacitor applications. Diam. Relat. Mater. 2018, 88, 23-31. [CrossRef]

8. Yang, C.-H.; Kuok, F.-H.; Liao, C.-Y.; Wan, T.-H.; Chen, C.-W.; Hsu, C.-C.; Cheng, I.-C.; Chen, J.-Z. Flexible reduced graphene oxide supercapacitor fabricated using a nitrogen dc-pulse atmospheric-pressure plasma jet. Mater. Res. Express 2017, 4, 025504. [CrossRef]

9. Chen, J.-Z.; Wang, C.; Hsu, C.-C.; Cheng, I.-C. Ultrafast synthesis of carbon-nanotube counter electrodes for dye-sensitized solar cells using an atmospheric-pressure plasma jet. Carbon 2016, 98, 34-40. [CrossRef]

10. Wang, J.-G.; Yang, Y.; Huang, Z.-H.; Kang, F. Synthesis and electrochemical performance of $\mathrm{MnO}_{2} / \mathrm{CNTs}^{-\mathrm{embedded}}$ carbon nanofibers nanocomposites for supercapacitors. Electrochim. Acta 2012, 75, 213-219. [CrossRef]

11. Hosseini, M.G.; Shahryari, E. A novel high-performance supercapacitor based on chitosan/graphene oxide-MWCNT/polyaniline. J. Colloid Interface Sci. 2017, 496, 371-381. [CrossRef]

12. Chien, H.-H.; Liao, C.-Y.; Hao, Y.-C.; Hsu, C.-C.; Cheng, I.-C.; Yu, S.; Chen, J.-Z. Improved performance of polyaniline/reducedgraphene-oxide supercapacitor using atmospheric-pressure-plasma-jet surface treatment of carbon cloth. Electrochim. Acta 2018, 260, 391-399. [CrossRef]

13. Antolini, E. Graphene as a new carbon support for low-temperature fuel cell catalysts. Appl. Catal. B-Environ. 2012, 123, 52-68. [CrossRef] 
14. Yin, Z.; Zhu, J.; He, Q.; Cao, X.; Tan, C.; Chen, H.; Yan, Q.; Zhang, H. Graphene-based materials for solar cell applications. Adv. Energy Mater. 2014, 4, 1300574. [CrossRef]

15. Arivu, M.; Masud, J.; Umapathi, S.; Nath, M. Facile synthesis of $\mathrm{Ni}_{3} \mathrm{~B} / \mathrm{rGO}$ nanocomposite as an efficient electrocatalyst for the oxygen evolution reaction in alkaline media. Electrochem. Commun. 2018, 86, 121-125. [CrossRef]

16. Rames, S.; Yadav, H.M.; Lee, Y.J.; Hong, G.W.; Kathalingam, A.; Sivasamy, A.; Kim, H.S.; Kim, H.S.; Kim, J.H. Porous materials of nitrogen doped graphene oxide@SnO2 electrode for capable supercapacitor application. Sci. Rep. 2019, 9. [CrossRef]

17. Zheng, W.; Li, S.; Yu, X.; Chen, C.; Huang, H.; Huang, Y.; Li, L. Synthesis of hierarchical reduced graphene oxide $/ \mathrm{SnO}_{2} / \mathrm{polypyrrole}$ ternary composites with high electrochemical performance. Mater. Res. Bull. 2016, 80, 303-308. [CrossRef]

18. Lim, S.P.; Huang, N.M.; Lim, H.N. Solvothermal synthesis of $\mathrm{SnO}_{2}$ /graphene nanocomposites for supercapacitor application. Ceram. Int. 2013, 39, 6647-6655. [CrossRef]

19. Xiang, C.; Li, M.; Zhi, M.; Manivannan, A.; Wu, N. A reduced graphene oxide $/ \mathrm{Co}_{3} \mathrm{O}_{4}$ composite for supercapacitor electrode. J. Power Sources 2013, 226, 65-70. [CrossRef]

20. An, H.; Wang, Y.; Wang, X.; Zheng, L.; Wang, X.; Yi, L.; Bai, L.; Zhang, X. Polypyrrole/carbon aerogel composite materials for supercapacitor. J. Power Sources 2010, 195, 6964-6969. [CrossRef]

21. Ramya, R.; Sivasubramanian, R.; Sangaranarayanan, M. Conducting polymers-based electrochemical supercapacitors-Progress and prospects. Electrochim. Acta 2013, 101, 109-129. [CrossRef]

22. Snook, G.A.; Kao, P.; Best, A.S. Conducting-polymer-based supercapacitor devices and electrodes. J. Power Sources 2011, 196, 1-12. [CrossRef]

23. Liu, Y.; Qu, G.; Sun, Q.; Jia, H.; Wang, T.; Zhu, L. Endogenously activated persulfate by non-thermal plasma for Cu(II)-EDTA decomplexation: Synergistic effect and mechanisms. Chem. Eng. J. 2021, 406, 126774. [CrossRef]

24. Bai, B.C.; Lee, H.-U.; Lee, C.W.; Lee, Y.-S.; Im, J.S. N2 plasma treatment on activated carbon fibers for toxic gas removal: Mechanism study by electrochemical investigation. Chem. Eng. J. 2016, 306, 260-268. [CrossRef]

25. Zhang, T.; Wu, J.; Chen, J.; Pan, Q.; Wang, X.; Zhong, H.; Tao, R.; Yan, J.; Hu, Y.; Ye, X. Activating Titanium Metal with $\mathrm{H}_{2}$ Plasma for the Hydrogen Evolution Reaction. ACS Appl. Mater. Interfaces 2021, 13, 24682-24691. [CrossRef]

26. Tao, L.; Duan, X.; Wang, C.; Duan, X.; Wang, S. Plasma-engineered $\mathrm{MoS}_{2}$ thin-film as an efficient electrocatalyst for hydrogen evolution reaction. Chem. Commun. 2015, 51, 7470-7473. [CrossRef] [PubMed]

27. Abuzairi, T.; Okada, M.; Mochizuki, Y.; Poespawati, N.R.; Purnamaningsih, R.W.; Nagatsu, M. Maskless functionalization of a carbon nanotube dot array biosensor using an ultrafine atmospheric pressure plasma jet. Carbon 2015, 89, 208-216. [CrossRef]

28. Hsu, C.-T.; Tsai, J.-H.; Huang, T.-M.; Hsin, J.-C.; Chen, J.-Z.; Lee, B.-S.; Yang, T.-C. Atmospheric pressure plasma jet treatment enhances the effect of Alloy Primer on the bond strength between polymethyl methacrylate and stainless steels: Application for retention of magnetic attachment to resin denture base. Colloids Surf. B Biointerfaces 2021, 197, 111440. [CrossRef]

29. Puač, N.; Gherardi, M.; Shiratani, M. Plasma agriculture: A rapidly emerging field. Plasma Process. Polym. 2018, 15, 1700174. [CrossRef]

30. Graves, D.B. Low temperature plasma biomedicine: A tutorial review. Phys. Plasmas 2014, 21, 080901. [CrossRef]

31. Chen, J.-Z.; Hsu, C.-C.; Wang, C.; Liao, W.-Y.; Wu, C.-H.; Wu, T.-J.; Liu, H.-W.; Chang, H.; Lien, S.-T.; Li, H.-C. Rapid atmosphericpressure-plasma-jet processed porous materials for energy harvesting and storage devices. Coatings 2015, 5, 26-38. [CrossRef]

32. Gerullis, S.; Kretzschmar, B.S.M.; Pfuch, A.; Beier, O.; Beyer, M.; Grünler, B. Influence of atmospheric pressure plasma jet and diffuse coplanar surface barrier discharge treatments on wood surface properties: A comparative study. Plasma Process. Polym. 2018, 15, 1800058. [CrossRef]

33. Alotaibi, F.; Tung, T.T.; Nine, M.J.; Kabiri, S.; Moussa, M.; Tran, D.N.; Losic, D. Scanning atmospheric plasma for ultrafast reduction of graphene oxide and fabrication of highly conductive graphene films and patterns. Carbon 2018, 127, 113-121. [CrossRef]

34. Kuok, F.-H.; Liao, C.-Y.; Wan, T.-H.; Yeh, P.-W.; Cheng, I.-C.; Chen, J.-Z. Atmospheric pressure plasma jet processed reduced graphene oxides for supercapacitor application. J. Alloys Compd. 2017, 692, 558-562. [CrossRef]

35. Chen, J.-Z.; Liao, W.-Y.; Hsieh, W.-Y.; Hsu, C.-C.; Chen, Y.-S. All-vanadium redox flow batteries with graphite felt electrodes treated by atmospheric pressure plasma jets. J. Power Sources 2015, 274, 894-898. [CrossRef]

36. Chen, Y.; Zhang, X.; Yu, P.; Ma, Y. Stable dispersions of graphene and highly conducting graphene films: A new approach to creating colloids of graphene monolayers. Chem. Commun. 2009, 4527-4529. [CrossRef] [PubMed]

37. Xu, J.; Wang, D.; Yuan, Y.; Wei, W.; Duan, L.; Wang, L.; Bao, H.; Xu, W. Polypyrrole/reduced graphene oxide coated fabric electrodes for supercapacitor application. Org. Electron. 2015, 24, 153-159. [CrossRef]

38. Chang, J.-H.; Lin, M.-F.; Kuo, Y.-L.; Yang, C.-R.; Chen, J.-Z. Flexible rGO-SnO 2 supercapacitors converted from pastes containing $\mathrm{SnCl} 2$ liquid precursor using atmospheric-pressure plasma jet. Ceram. Int. 2021, 47, 1651-1659. [CrossRef]

39. Keawploy, N.; Venkatkarthick, R.; Wangyao, P.; Zhang, X.; Liu, R.; Qin, J. Eco-friendly conductive cotton-based textile electrodes using silver-and carbon-coated fabrics for advanced flexible supercapacitors. Energy Fuels 2020, 34, 8977-8986. [CrossRef]

40. Li, Y.; Zhang, Y.; Zhang, H.; Xing, T.-L.; Chen, G.-Q. A facile approach to prepare a flexible sandwich-structured supercapacitor with rGO-coated cotton fabric as electrodes. RSC Adv. 2019, 9, 4180-4189. [CrossRef]

41. Dubal, D.P.; Lee, S.H.; Kim, J.G.; Kim, W.B.; Lokhande, C.D. Porous polypyrrole clusters prepared by electropolymerization for a high performance supercapacitor. J. Mater. Chem. 2012, 22, 3044-3052. [CrossRef] 
42. Ardizzone, S.; Fregonara, G.; Trasatti, S. "Inner" and "outer" active surface of $\mathrm{RuO}_{2}$ electrodes. Electrochim. Acta 1990, 35, $263-267$. [CrossRef]

43. Tiwari, P.; Jaiswal, J.; Chandra, R. Hierarchal growth of $\mathrm{MoS}_{2} @ \mathrm{CNT}$ heterostructure for all solid state symmetric supercapacitor: Insights into the surface science and storage mechanism. Electrochim. Acta 2019, 324, 134767. [CrossRef]

44. Huang, C.; Zhang, J.; Young, N.P.; Snaith, H.J.; Grant, P.S. Solid-state supercapacitors with rationally designed heterogeneous electrodes fabricated by large area spray processing for wearable energy storage applications. Sci. Rep. 2016, 6, 1-15. [CrossRef]

45. Shao, J.; Zhou, X.; Liu, Q.; Zou, R.; Li, W.; Yang, J.; Hu, J. Mechanism analysis of the capacitance contributions and ultralong cyclingstability of the isomorphous $\mathrm{MnO}_{2} @ \mathrm{MnO}_{2}$ core/shell nanostructures for supercapacitors. J. Mater. Chem. A 2015, 3, 6168-6176. [CrossRef]

46. Gund, G.S.; Dubal, D.P.; Chodankar, N.R.; Cho, J.Y.; Gomez-Romero, P.; Park, C.; Lokhande, C.D. Low-cost flexible supercapacitors with high-energy density based on nanostructured $\mathrm{MnO}_{2}$ and $\mathrm{Fe}_{2} \mathrm{O}_{3}$ thin films directly fabricated onto stainless steel. Sci. Rep. 2015, 5, 1-13. [CrossRef]

47. Zhang, Y.; Liu, Y.; Bai, Y.; Liu, Y.; Xie, E. Boosting the electrochemical properties of carbon materials as bipolar electrodes by introducing oxygen functional groups. RSC Adv. 2020, 10, 35295-35301. [CrossRef] 